\title{
INTELLIGENCE FUNCTIONS DISORDERS IN PATIENTS WITH COMPLEX PARTIAL EPILEPSY
}

\author{
Florindo Stella ${ }^{1}$, Jayme Antunes Maciel ${ }^{2}$
}

\begin{abstract}
Objective: To compare the performance of patients with complex partial epilepsy with the normal controls in the subtests of an instrument used to assess intelligence function. Method: Fifty epileptic patients, whose ages ranged from 19 to 49 years and 20 normal controls without any neuropsychiatric disorders. The Wechsler-Bellevue adult intelligence test was applied in groups, epileptic patients and control subjects. This test is composed of several subtests that assess specific cognitive functions. A statistical analysis was performed using non-parametric tests. Results: All the Wechsler-Bellevue subtests revealed that the intelligence functions of the patients were significantly inferior to that of the controls $(p<0.05)$. This performance was supported by the patient's complaints in relation to their cognitive performance. Conclusion: Patients with complex partial epilepsy presented poorer results in the intelligence test when compared with individuals without neuropsychiatric disorders.
\end{abstract}

KEY WORDS: epilepsy, cognitive functions, intelligence.

\begin{abstract}
Distúrbios das funções da inteligência em pacientes com epilepsia parcial complexa
RESUMO - Objetivo: Comparar o desempenho de pacientes com epilepsia parcial complexa e de sujeitoscontrolesquanto ao desempenho nos subtestes de um instrumento para avaliação dasfunções da inteligência. Método: Foram estudados 50 pacientes epilépticos em série consecutiva, com idade entre 19 e 49 anos. Também foram avaliados 20 sujeitos-controles, sem enfermidades neuropsiquiátricas, para efeito comparativo. Foi aplicado teste de inteligência para adultos de Wechsler-Bellevue em dois grupos, de pacientes e controles. Este teste é constituído de vários subtestes que avaliam funções cognitivas espećíficas. Os procedimentos de análise estatística foram efetuados segundo testes não-paramétricos. Resultados: Em todos ossubtestes do Wechsler-Bellevue, os pacientes apresentaram desempenho dasfunções da inteligência significativamente inferior ao dos controles $(p<0,05)$, resultados corroborados pelas queixas dos mesmos quanto às funções cognitivas. Conclusão: Pacientes com epilepsia parcial complexa apresentaram resultados significativamente inferiores no teste de inteligência quando comparados aos dos sujeitos sem epilepsia.
\end{abstract}

PALAVRAS-CHAVE: epilepsia, funções cognitivas, inteligência.

Complex partial epilepsy ismanifested by various psychopathological conditions such as psychotic symptoms ${ }^{1}$, depressive disorders², "pseudo-seizures" type disorders, and others ${ }^{1,3}$. Generally, these psychopathological alterations reflect a functional disorder of the limbic system². Patients with this type of epilepsy and acute compromise of the hippocampusalso tend to present cognitive disorders, especially verbal memory disorders ${ }^{4}$, altered perspective activity and semantic memory for language content ${ }^{5}$. Attention disorders have also been associated with an epileptic condition ${ }^{6}$, and during child- hood, temporal lobe epilepsy, besidesattention disorders, may also interfere in the learning process?. Other cognitive processes such as organization of logical thinking aswell as reasoning structure and expression may be affected in patients with temporal lobe epilepsy.

Therefore Aikia et al. ${ }^{9}$ applied the WAIS-R test (Wechsler Adult Intelligence Scale Revised) to 56 adult patients with complex partial epilepsy and verified that $52 \%$ presented altered cognitive functions. Using the WAIS-R, Williamson et al. ${ }^{10}$ also verified high levels of compromised reasoning capac-

Neuropsychology and Behavior Neurology Unit, Department of Neurology, Faculty of Medical Sciences, State University of Campinas (UNICAMP), Campinas SP, Brazil: ${ }^{1}$ Assistant Professor of Psychology and Neuropsychology, Institute of Biosciences, Paulista State University (UNESP), Rio Claro S.P, Brazil; '2Associated Professor of Neurology, UNICAMP, Campinas SP, Brazil. This study was supported by FAPESP, São Paulo, Brazil.

Received 11 May 2004, received in final form 3 August 2004. Accepted 12 August 2004.

Dr. Florindo Stella - Instituto de Biociências/Psicologia - Universidade Estadual Paulista - CP 199 - 13506-900 Rio Claro SP - Brasil. E-mail: fstella@rc.unesp.br 
ity in patientswith temporal lobe epilepsy. Obviously, several factors such as the nature, severity, chronicity and frequency of the seizures, involvement of brain structures, neurotoxicity of the antiepileptic drugs and the patient's psychosocial difficulties are responsible for determining alterations in the cognitive function of epileptic patients ${ }^{8,11}$.

This research was undertaken with the purpose of studying the performance of the intelligence func tions in patientswith complex partial epilepsy and comparing thisperformance with that of individuals without this clinical condition.

\section{METHOD}

Subjects - A study was conducted on 50 consecutive patients, aged between 19 and 49 years, with complex partial epilepsy and under follow-up at the Outpatient's Epilepsy Unit, State University of Campinas, UNICAMP. A control group of 20 individuals without epilepsy or any other neurological or psychiatric disorder and with similar socioeconomic conditions, cultural level, education and in the same age group as the patientswere evaluated for comparative purposes.

The research obeyed the ethical standards set by the Service and the individuals were volunteers who participated after signing an informed consent.

\section{Methodology}

Criteria for inclusion and exclusion - Patients who participated in thisstudy had complex partial epilepsy, used antiepileptic medication regularly and the serum levels were maintained within the therapeutic range. Patients had to be free from any neuropsychiatric disorders that may compromise their cognitive functions. Patients who used antiepileptic medication irregularly or antiepileptic serum dose levels that were not in conformity with the recommended therapy and also those with psychopathological symptomssuch as depression, psychotic disordersor any other symptom that may interfere in their cognitive performance were excluded. A detailed clinical interview and the Montgomery-Asberg depression rate scale ${ }^{12}$, adapted for the Brazilian population by Dractu et al. ${ }^{13}$ were applied to identify these psychopathological symptoms, especially depression. Therefore, the final sample consisted of 50 patients. The dinical interview and the above cited depression scale was also applied to the control subjects so that individuals with neuropsychiatric disorders could be excluded. This resulted in a control group with 20 individuals.

Clinical diagnosis- The dinical diagnosis of complex partial epilepsy by the team that regularly attends patients at the Epilepsy Ambulatory Unit included type of seizure, date of onset, seizure frequency, antiepileptic medication, serum dosage (whether within the therapeutic range or not) and electroencephalogram characteristics (initiating in the temporal region). Other procedu- res requested were magnetic resonance to verify the presence of structural lesions in the mesial regions of the temporal lobe and the interictal brain SPECT to check hypoperfusion in these regions.

Neuropsychological assessment - According to the criteria adopted in this study, intelligence is characterized by integrated cognitive processes that include the capacity to coherently organize information as well as understand and reach a logical inference when faced with challenging situations, perceive and structure environmental stimulus, perform logical-arithmetic operations, associate ideas, execute activities and cognitively program behavior. Thismental process is verified by the WechslerBellevue adult intelligence test (adapted for the Brazilian population by Moraes, Andrade and Alves, s/d; apud Stel$\mathrm{Ia}^{14}$ and is the neuropsychological instrument used in this study. The Wechsler-Bellevue adult intelligence scale has the same subtests as the revised test (WAIS-R) and is also similar to each other with regard to internal structure and objectives. The main difference between them is the manner in which the subtests are executed by the individual. The Wechsler-Bellevue is easier to apply, quicker and less tiring than the WAIS - R. This instrument is composed of several subtests that evaluate certain intelligence functions: 1) Story arrangement: the capacity to logically interpret stimuli, arrange visual images and verbal language in correct story sequence. 2) Comprehension: the capacity to logically interpret content, make inferencesand resolve problem-situations. 3) Figure completion: ability to perceive, elaborate and coherently organize and construct logical thinking. 4) Arithmetic reasoning: capacity for logical arithmetic reasoning and the ability to perform mathematical operations. 5) Similarities: associating ideas, analyzing details, establishing relationships between stimuli regarding similarities and differences. 6) Mosaic: executive functions such as concentrated attention, constructing cognitive ideas, visual-spatial perception, spatial-logical reasoning and ability to self correct behavior whenever necessary. 7) Coding pattern: executive functions such as concentrated attention, cognitive programming and visual-perceptual capacity. All 50 patients and the 20 control individualsunderwent the same Neuropsychological Assessment battery.

Statistical analysis - The statistical assessment, which was performed by the Research Commission, Faculty of Medical Sciences, UNICAMP, used the non-parametric Mann - Whitney and chi-square tests with significance

Table 1. Social and demographic data of patients and controls.

\begin{tabular}{lll}
\hline Data & Patients & Controls \\
\hline Age (mean) & 32.5 years & 36.6 years \\
Gender & Men: 18 (36\%) & Men: 4 (20\%) \\
& Women: 32 (64\%) & Women:16 (80\%) \\
Education level & 7.6 years & 7.4 years \\
Total & 50 & 20 \\
\hline
\end{tabular}


Table 2. Clinical data of 50 epileptic patients.

\begin{tabular}{ll}
\hline & Clinical data \\
\hline Average age at seizure onset & 14.1 years \\
Average disease duration & 18.1 years \\
Average interval between seizures & 33.4 days \\
Diagnosis & Complex partial epilepsy \\
Electroencephalogram & Epileptic pattern in 29 patients (58\%). Normal in 21 patients (42\%) \\
Antiepileptic medication serum dosage & All 50 patients within the recommended therapeutic range in relation to the \\
& respective medication being used. \\
\hline
\end{tabular}

value at $5 \%(p=0.05)$ to assess the correlations of the variables and categories.

\section{RESULTS}

Social and demographic data - Age and educational level were particularly relevant factorsin the context of the neuropsychological assessment. In this study, no significant statistical difference was

Table 3. The Wechsler-Bellevue scale: a comparison results in controls and patients with complex partial epilepsy.

\begin{tabular}{lccc}
\hline Subtests & $\begin{array}{c}\text { Patients } \\
(\mathrm{N}=50)\end{array}$ & $\begin{array}{c}\text { Controls } \\
(\mathrm{N}=20)\end{array}$ & $\mathrm{p}$ \\
\hline Stories & 13.7 & 18.7 & $0.0021^{*}$ \\
Comprehension & 3.1 & 5.7 & $0.0015^{*}$ \\
Figure completion & 4.2 & 5.7 & $0.0464^{*}$ \\
Arithmetic reasoning & 3.3 & 5.2 & $0.0338^{*}$ \\
Similarities & 2.8 & 5.0 & $0.0210^{*}$ \\
Mosaic & 21.3 & 29.9 & $0.0075^{*}$ \\
Coding & 20.0 & 29.2 & $0.0001^{*}$ \\
\hline
\end{tabular}

*statistically significant

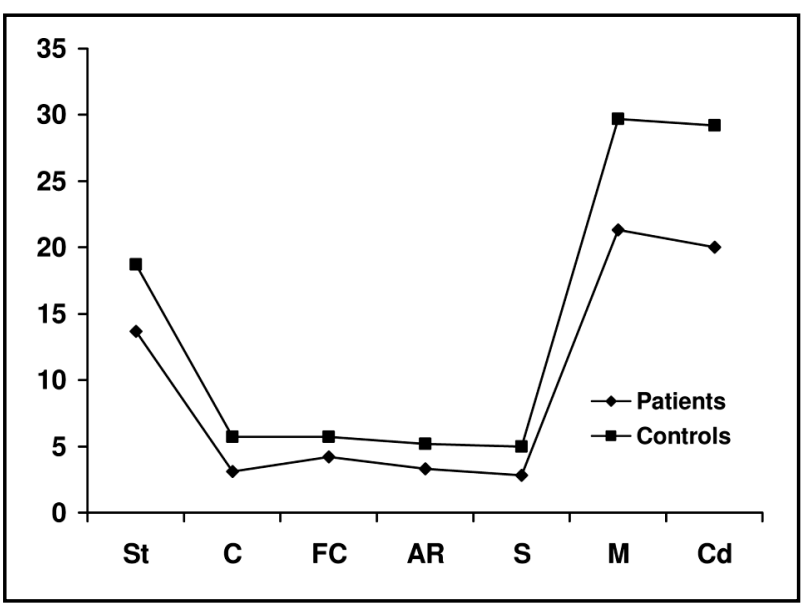

Fig. Weschler-Bellevue subtests compared in a group of 50 partial complex epilepsy patients and 20 normal controls. St; stories, C; comprehension, FC; figure completion, AR; arithmetic reasoning, S; similarities, $\mathrm{M}$; mosaic, $\mathrm{Cd}$; Coding. observed between patients and controls when these factors were compared (age: $p=0.08$; education $\mathrm{p}=0.06$; Mann-Whitney nonparametric test). Table 1 displays the social and demographic data.

Clinical data and subsidiary exams- All the patients presented complex partial epilepsy with overall onset of seizure during adolescence, around the age of 14.1 years. The chronic epileptic condition when this study was being conducted revealed an average duration of 18.1 years with relatively frequent interictal intervals of 33.4 days (mean) between one ictal episode and the other. Although all the patients were clinically diagnosed as complex partial epilepsy by the team of neurologistsat the Epilepsy OutpatientsUnit, the encephalogram displayed tracesthat were compatible with thiscondition in 29 patients (58\%), while in the remaining 21 patients, the traces were considered within the limits of normality. Table 2 displays these data.

Assessment of intelligence functions (Figure) The performance of intelligence functions presented by the patients in all the Wechsler-Bellevue subtests was inferior to that of the controls and the difference between the groupswas statistically significant ( $<\varangle 0.05$; nonparametric Mann-Whitney test). Figure displays these data.

The difference between patients and controls was particularly significant, more so with regard to the subtests Coding, Comprehension, story arrangement and mosaic. Likewise, the patients' performance wasalso poorer than the controlsin the subtests figure completion, arithmetic reasoning and similarities. Although this difference was statistically significant, it was smaller than in the previous subtests. These data are presented in Table 3.

Patients, who present early complex partial seizuresand a longer epileptic condition, concomitantly present cognitive type of complaints. The statistical analysis confirmed a correlation between chro- 
nic epilepsy and the subtests, but this correlation wasnot statistically significant ( $p>0.05$; Mann-Whitney nonparametric test).

Comprehension was the subtest most affected by frequent seizures and the correlation between these two variables was statistically significant ( $p=0.0345 ;$ Mann-Whitney nonparametric test). A correlation was also observed between frequency of seizures and the rest of the subtests, but without significance ( $p>0.05$; Mann-Whitney nonparametric test).

The mean age of the patients at seizure onset was 14.1 years, which meant onset was during adolescence and while the study was being conducted, the duration of this epileptic condition in 13 patients $(26 \%)$ went up to 10 years and in the case of 37 patients $(74 \%)$ the duration was greater. The subtest performance of patients with over 10 years of chronic seizure wasmore affected than in the case of patients with a shorter duration of the epileptic condition, but the difference between these two groups of patients was not statistically significant ( $p>0.05$; chi-square test).

With regard to the frequency of seizures, the data reveals a distinction between two groups of patients: one group of 35 patients (70\%) with an interictal interval of up to 30 days and the other group of 15 patients (30\%) with an interictal interval of 31 days or more. The group of patients with a shorter interictal interval (up to 30 days) presented greater compromise in the subtests than those with a larger interval ( 31 daysor more). However, the difference between both groups was not statistically significant ( $p>0.05$; chi-square test).

\section{DISCUSSION}

Our results are in accordance with those obtained by other investigationsin which neuropsychological assessments, particularly the WAIS-R, were performed in adult patients with temporal lobe epilepsy. These investigations, in general, aimed at overall alterations of cognitive functions ${ }^{10,15-17}$. Other authors have highlighted disorders that are specifically related to semantic memory and associated with hippocampus disruption ${ }^{9,18-20}$.

The performance of the patients in our study was significantly poorer than that of the controls in relation to the Wechsler-Bellevue intelligence test. A significant difference was observed between both groups, but in the case of the subtests comprehension, stories, mosaic and coding, the difference was more accentuated. The mosaic and coding subtests evaluate executive functions. Mental organization and the expression of these functions involve several psychic processes such ascognitive programming of sequentially constructed logical actions, concentrated attention capacity and visual-spatial perception. The subtest comprehension, in turn, evaluates the inference of several mental processes such as the capacity to understand content that demands refined logical interpretation due to its complexity. It also investigates the skill for seeking solutions to overcome challenges such as problem-situations. The subtest story arrangement allowsthe inference of several mental mechanisms such as the capacity for logical interpretation of complex situations and the capacity of the individual to coherently organize cognitive content. It also assesses the structure of thoughts verbally expressed.

In the other subtests-figure completion, arithmetic reasoning and similarities, the logical performance presented by the patients was significantly inferior to that of the controls, but the difference between the two groups was less accentuated than in the previous subtests. It should be highlighted that the subtest figure completion investigates the ability of the individual to coherently organize the data obtained through this type of perception.

The subtest arithmetic reasoning evaluates the individual's capacity to elaborate operations that process calculation and the quality of mathematical-logical thinking. The subtest similarities infer the individual's capacity to establish a relationship between ideas, analyze details of a certain phenomenon and globally correlate all these details. It also assesses similar and dissimilar relationships of this phenomenon.

A comparison between interictal intervals and subtest performance revealed that patients with intervals of less than 30 days demonstrated cognitive performance inferior to that of patients with larger intervals, even though the difference between both groups was not statistically significant. However, patients with interictal intervals of less than 30 days presented relevant subjective cognitive complaints and more frequently than patients with longer intervals.

The performance of patients with up to 10 years of disease duration presented no significant difference when compared with patients with a greater duration. Nonetheless, there were relevant subjective complaints compatible with cognitive difficul- 
ties, especially in patients with more than 10 years of disease duration. Although our study did not reveal a statistically significant correlation between disease duration and cognitive compromise, other studies have suggested that chronic complex partial epilepsy may cause cognitive disorders, especially in the case of short term memory ${ }^{21}$.

The mean age of seizure onset in our study was 14.1 years, which differed from other studies that verified seizure onset before the age of five ${ }^{22,23}$. Early onset seizures that extend for a long time reveal more accentuated compromise of brain function and an increased risk of aggravation of the cognitive functions ${ }^{24}$.

It is important to underscore the fact that cognitive activity tends to suffer interference from various factors that cannot always be controlled and interfere in the patient's cognitive performance. Some of these factors are outstanding such as neuropathological compromise sub-adjacent to seizures, type of seizure, age at onset, frequency of seizures, electroencephalographic pattern ${ }^{8,11}$. Antiepileptic drugs, especially the older ones like phenobarbital, may also have a harmful effect on overall cognitive functioning, compromising several functions such as concentrated attention, alertness, recent memory, visual-spatial memory, capacity for problem resolution and routine activity ${ }^{8,11,25}$. Although these substances harm cognitive functions, epileptic seizure control, particularly with the more recent drugs and a monotherapeutic regimen, contributes towardsthe preservation of cognitive quality ${ }^{26,27}$. Besidesthis, several studies have demonstrated that uncontrolled epilepsy presents greater risk of cognitive compromise than medication-controlled seizures, especially the more recent medications $s^{10,20,28}$.

Finally, patientswith complex partial epilepsy present significant compromise of intelligence functionsaccording to the Wechsler-Bellevue Intelligence Test when compared with individuals without this clinical condition. Poorer performance by these patients is probably due to the interference of variousfactorsthat simultaneously influence cognitive performance such as type of seizure, onset age, seizure frequency, electroencephalographic pattern, presence of structural alterationsin the mesial region of the temporal lobe, antiepileptic drugsetc. Further research on the interference of these factors in the organization of intelligence functions would enhance information regarding the relationship between epilepsy and cognition.

\section{REFERENCES}

1. Kristensen $\mathrm{O}$, Alving J. Pseudoseizures: risk factors and prognosis. Acta Neurol Scand 1992;85:177-180.

2. Perini GI, Tosin C, Carraro C, et al. Interictal mood and personality disorders in temporal lobe epilepsy and juvenile myoclonic epilepsy. J Neurol Neurosurg Psychiatry 1996;61:601-605.

3. Oana Y. Epileptic seizures and pseudoseizures from the viewpoint of the hierarchy of consciousness. Epilepsia 1998;39(Suppl 5):S21-S25.

4. Hermann BP, Wyler AR, Richey ET, Rea JM. Memory function and verbal learning ability in patients with complex partial seizures of temporal lobe origin. Epilepsia 1987;28,547-554.

5. Engel J. Introduction to temporal lobe epilepsy. Epilep Res 1996;26:141150.

6. Stella F., Maciel JA. Attentional disorders in patients with complex partial epilepsy. Arq Neuropsiquiatr 2003;61:355-358.

7. Croona C, Kihlgren M, Lundberg S, Eeg-Olofsson O, Eeg-Olofsson KE. Neuropsychological findings in children with benign childhood epilepsy with centrotemporal spiles. Dev Med Child Neurol 1999;41:813-818.

8. Binnie CD, Channon S, Marston D. Learning disabilities in epilepsy: neurophysiological aspects. Epilepsia 1990;31(Suppl 4):S2-S8.

9. Aikia M, Kalviainen R, Riekkinen P. Verbal learning and memory in newly diagnosed partial epilepsy. Epilep Res 1995;22:157-164.

10. Williamson PD, French JA, Thadani M, et al. Characteristics of medical temporal lobe epilepsy: II. Interictal and ictal scalp electroencephalography, neuropsychological testing, neuroimaging, surgical results, and pathology. Ann Neurol 1993;34:781-787.

11. Motamedi G, Meador K Epilepsy and cognition. Epilep Behav 2003;4(Suppl 2):S25-S38.

12. Montgomery AS, Asberg MNew depression scale designed to be sensitive to change. Br J Psychiatry 1979;134:382-389.

13. Dractu L, Ribeiro LC, Calil HM. Escalas de avliação da depressão e sua utilidade clínica: Hamilton, Montgomery-Asberg e visual-análoga do humor. Rev Assoc Bras Psiquiatria 1985;7:59-65.

14. Moraes R. Teste de inteligência de adultos de Wechsler-Bellevue. CELPA - Centro de Psicologia Aplicada. In Stella F. Distúrbios cognitivos na epilepsia. Tese de Doutorado. Universidade Estadual de Campinas. Campinas, 1998;102-109.

15. Verma NP, Twitty GR, Fuerst DR. Event-related potentials in complex partial seizures. Brain Topogr 1993;6:35-41.

16. Selwa LM, Berent S, Giordani B, Henry TR, Buchtel HA, Ross DA. Serial cognitive testing in temporal loge epilepsy: longitudinal changes with medical and surgical therapies. Epilepsia 1994;35:743-749.

17. Jokeit $\mathrm{H}$, Ebner A. Long term effects of refractory temporal lobe epilepsy on cognitive abilities: a cross sectional study. J Neurol Neurosurg Psychiatry 1999;67:44-50.

18. Kilpatrick C, Murrie V, Cook M, Andrewes D, Desmond P, Hopper J Degree of left hippocampal atrophy correlates with severity of neuropsychological deficits. Seizure 1997;6:213-218.

19. Baxendale SA. The role of the hippocampus in recognition memory. Neuropsychologia 1997;35:591-598.

20. Hermann BP, Seidenberg M, Schoenfeld J, Davies K. Neuropsychological characteristics of the syndrome of mesial temporal lobe epilepsy. Arch Neurol 1997;54:369-376.

21. Mataro-Serrat M, Junque-Plaja C. Memory and epilepsy. Rev Neurol (Barc) 1997;25:1241-1245.

22. O'Lery DS, Lovell MR, Sackellares JC, et al. Effects of age of onset of partial and generalized seizures on neuropsychological performance in childern. J Nerv Mental Dis 1983;17:624-629.

23. Rodin EA, Schmaltz S, Twitty G. Intellectual function in patients with childhood epilepsy. Dev Med Child Neurol 1986;28:25-33.

24. Aldenkamp AP. Effect of seizures and epileptiform discharges on cognitive function. Epilepsia 1997;38(Suppl 1):S52-S55.

25. Sabers A, Moller A, Dam M, Smed A, et al. Cognitive function and anticonvulsivant therapy: effect of monotherapy in epilepsy. Acta Neurol Scand 1995;92:19-27.

26. Powell AL, Yudd A, Zee P, Mandelbaum DE. Attention deficit hperactivity disorder associated with orbitofrontal epilepsy in a father and a son. Neurpsych Neuropsychol Behav Neurol 1997;10:151-154.

27. Helmstaedter C, Kurthen M, Lux S, Reuber M, Elger CE. Chronic epilepsy and cognition: a longitudinal study in temporal lobe epilepsy. Ann Neurol 2003;54:425-432.

28. Vermeulen J, Akdenkamp AP. Cognitive side-effects of chronic antiepileptic drug treatment: a review of 25 years of research. Epilep Res 1995;22: 65-95. 